\title{
Sleep disturbance as a universal risk factor for relapse in addictions to psychoactive substances
}

\author{
Kirk J. Brower *, Brian E. Perron \\ University of Michigan, Department of Psychiatry, 4250 Plymouth Rd., SPC 5740, Ann Arbor, MI 48109-2700, USA
}

\section{A R T I C L E I N F O}

\section{Article history:}

Received 6 October 2009

Accepted 10 October 2009

\begin{abstract}
S U M M A R Y
Relapse to uncontrolled use of a psychoactive substance is arguably the single most defining characteristic of an addiction. Relapse following addiction treatment is very common with serious consequences to individuals, families, and the public system of care, making predictors of relapse a highly significant area of study. Before the turn of the century, most of the addiction treatment outcome literature focused on psychosocial predictors of relapse. More recently, investigating biological predictors of relapse specifically and treatment outcome broadly has gained momentum. This line of research has linked sleep disturbances to the risk of relapse among persons who are recovering from an alcohol addiction. Given common neurobiological and psychosocial processes in sleep and addictive behaviors, we hypothesize that the link between sleep disturbance and relapse risk observed among alcohol addiction generalizes to all other types of psychoactive substances. This hypothesis has the potential for helping develop more effective and targeted treatment approaches for persons with addiction. As initial support for the hypothesis, this paper reviews evidence on common neurobiological processes among various types of psychoactive substances that suggests sleep is a universal risk factor for relapse. A conceptual framework is also presented to articulate causal mechanisms. The paper concludes with implications for research and practice.
\end{abstract}

(C) 2009 Elsevier Ltd. All rights reserved.

\section{Introduction}

Relapse to uncontrolled use of a psychoactive substance is arguably the single most defining characteristic of an addiction, a source of immense frustration that is accompanied by tragic consequences for patients and society, and a primary target for addiction treatment research. Unfortunately, relapse following addiction treatment is very common and, therefore, predictors of relapse are a highly significant area of study. Before the turn of the century, most of the addiction treatment outcome literature focused on psychosocial predictors of relapse, which includes the long list of variables in Table 1 . The underlying premise for studying these variables is that some might be modifiable, such as increasing self-efficacy, while other variables might respond optimally to specifically targeted treatment programs (e.g., gender, age).

More recently, investigating biological predictors of treatment outcome has gained momentum. Human studies in this area have shown relationships between relapse and (a) genetic variants [15], (b) size of specific brain structures [6], (c) functioning of various neurotransmitters and neuroendocrine systems [7-17], (d) activation of specific neuroanatomical regions as measured with functional brain imaging [18-20], and (e) patterns of electrophys-

\footnotetext{
* Corresponding author. Tel.: +1 734232 0294; fax: +1 7349987992.

E-mail address: kbrower@umich.edu (K.J. Brower).
}

iological brain patterns [21-26], including neurophysiological correlates of sleep [27-29]. The investigation of biological predictorswhich for the most part are neurobiological predictors-is consistent with the currently dominant paradigm in addiction research, namely that addiction is a brain disease. According to this paradigm, if we can delineate how the brain is altered in affected individuals, then we can improve upon treatment strategies by targeting these specific neurobiological alterations, for example, with pharmacotherapy agents. Not surprisingly for a dominant paradigm, a proliferation of scholarly reviews of the neurobiology of addiction has recently been published [30-33].

Of course, most experts would agree that addiction is not simply a brain disease, but rather a disorder that is strongly influenced by psychological, social, and cultural factors in addition to genetic, epigenetic, and neurobiological ones. While agreeing to the importance of non-biological factors in the etiology and course of substance use disorders, we will focus on a biological one, specifically sleep, which is also influenced strongly by psychosocial and cultural factors. Sleep disturbance offers a number of advantages when investigating predictors of addiction treatment outcome. For example, it is a common symptom across all substance-related withdrawal disorders recognized in the DSM-IV [34]. Psychological and pharmacological treatments are available to address sleep disturbances among persons with substance-related disorders $[35,36]$. Thus, with proper assessment and targeted sleep-related 
Table 1

Psychosocial predictors of relapse to substance dependence.

Demographics
Severity of dependence
Age at onset of problem use
Family history of substance use disorders
Co-occurring mental and other substance use disorders
Psychiatric severity
Character traits and disorders
Social support
Motivation for abstinence
Treatment adherence
Length of treatment stay
Participation in Alcoholics Anonymous or similar mutual-help groups
Therapeutic alliance
Self-efficacy

interventions, treatment providers can increase the likelihood of successful outcomes for this at-risk population. Finally, systematic investigation of the relationship between sleep disturbance and relapse can advance our knowledge on the basic science of addiction and treatments.

\section{Hypothesis}

Current research suggests that sleep disturbances among persons who are recovering from an alcohol addiction and have a sleep disturbance are at an elevated risk of relapse compared to those without a sleep disturbance. Given common neurobiological and psychosocial processes in sleep and addictive behaviors, we believe this sleep-related relapse risk for alcohol generalizes to all other types of psychoactive substances. In formalized terms, we hypothesize that persons who are recovering from an addiction to any psychoactive substance and have a sleep disturbance are at an increased risk of relapse compared to those without a sleep disturbance. In other words, sleep disturbance is a universal risk factor for relapse in addiction to all psychoactive substance. For this hypothesis, a sleep disturbance refers to any problems involved with falling asleep, staying asleep, distressing dreams, or inability to progress through normal stages of sleep.

We describe this hypothesis by first presenting research that shows an association between sleep disturbance and relapse among persons with an alcohol addiction. This is followed by a review of other research highlighting common neurobiological factors that provides a foundation for generalizing this association to other psychoactive substances. We then present sleep disturbance as a universal risk factor for relapse within a conceptual framework to describe the underlying causal mechanisms for this universal risk factor in relapse. We conclude with research and treatment implications based on the hypothesis.

\section{Evidence that sleep predicts relapse across psychoactive substances}

\section{Alcohol}

The largest body of evidence relating sleep disturbance to relapse involves studies of alcohol dependence, for which both subjective and objective measures of sleep at baseline have predicted subsequent relapse [27,37]. A 2003 review of the literature cited 12 publications from 1975 to 2001 by six different research groups demonstrating a relationship between sleep disturbance and relapse [38]. Since that time, at least three other reports have appeared which extend the evidence [39-41]. In general, the literature indicates that increased sleep latency and its subjective correlate (trouble falling asleep) as well as significantly more rapid eye movement (REM) sleep or "REM pressure" are replicated predictors of alcoholic relapse. Not included in this review is a 1973 publication citing dreams of alcohol-dependent patients as a prognostic factor [42]. Since then, another data-based publication describing polydrug users, including alcohol abusers, was consistent with this early observation [43]. Finally, a more recent report describing a series of cases stressed the importance of paying treatment attention to so-called "using" dreams in order to prevent relapse [44].

\section{Cocaine and amphetamines}

Although the literature on addiction-related dreaming and relapse is less substantial than for other sleep parameters, there are three reasons to take the phenomenon seriously. First is the inclusion of unpleasant, vivid dreams as a criterion symptom for both amphetamine and cocaine withdrawal [34]. Second, Sofuoglu and colleagues [45] reported from a cross-sectional survey that vivid, unpleasant dreams during cocaine withdrawal were associated with a history of addiction treatment, severe depression, and trading sex for cocaine or cocaine for sex; i.e., a more severe course of the disorder. Third is the association of rapid eye movement (REM) sleep pressure-a correlate of dream sleep-and relapse to alcohol dependence that has been independently documented by two different research groups $[29,46]$.

\section{Nicotine}

At least three recent studies are suggestive that events during the sleep period predicted relapse to smoking tobacco [47-49]. One of these reported that awakening during the night as measured by a nicotine withdrawal scale was negatively associated with abstinence for 6 months after starting treatment [47]. Another found that participants who had a history of smoking during their sleep period (after going to bed but before their final awakening in the morning) had an earlier time to their first smoking episode within 4 weeks of their quit date [49]. None of these studies employed polysomnography.

\section{Opioids}

We were unable to find evidence that poor sleep predicted relapse in patients dependent on opioids. Paradoxically, one recent study reported that poor sleep during opioid detoxification was associated with abstinence during a 4-week follow-up period [50]. The authors speculated that treatment staff may have given more attention to poor sleepers, resulting in better outcomes, but they could not support that explanation with data. Again, polysomnography was not performed.

\section{Sedative-hypnotics}

Regarding sedative-hypnotic dependence, there is general consensus that sleep disturbances perpetuate the disorder [51-54], but this relationship has not been formally tested.

\section{Conceptual framework for the sleep disturbance-relapse hypothesis}

The evidence that sleep disturbance is linked to relapse is strongest for alcohol dependence. Two sets of arguments for generalizing the link between sleep disturbance and relapse to other psychoactive substances are provided below. The first of these arguments is based on the commonality of sleep disturbances across psychoactive substances, while the second of these sections 
is based on the unique advantages of sleep disturbances as a predictor of treatment outcome.

\section{Commonality of sleep disturbance}

The phenomenology and course of acute withdrawal following a reduction in or discontinuation of dependent substance use is well-described diagnostically for six classes of substances, namely alcohol, amphetamines, cocaine, nicotine, opioids, and sedativehypnotics [34]. An examination of the diagnostic criteria across this list of substances reveals that sleep disturbances are the only group of symptoms that all withdrawal disorders share in common (refer to DSM-IV). Insomnia per se is listed across all substance withdrawal disorders, although sleep disturbance for some substances (cocaine and amphetamines) also includes hypersomnia or unpleasant, vivid dreams. Accordingly, we define insomnia as a universal withdrawal symptom, meaning that it occurs across all DSM-IV diagnoses of substance withdrawal. Likewise, if anxiety and depressed mood are combined to represent negative affect, then they form another group of universal withdrawal symptoms [55].

Depending on the class of substance and its elimination pharmacokinetics, acute withdrawal generally lasts 1 week or less, and sometimes for 3-4 weeks with longer-acting drugs. Other symptoms and their neurophysiological correlates have been shown to persist after acute withdrawal has abated in both humans and animal models [56]. These persistent symptoms, which include insomnia and negative affect, have been variously labeled as protracted withdrawal $[56,57]$ or subacute withdrawal symptoms [58]. Protracted or subacute withdrawal can be defined as a constellation of symptoms and neurobiological alterations that (a) persist beyond the time-course of acute substance withdrawal and (b) increase the risk for relapse. The notion of protracted or subacute withdrawal implies that its symptoms begin during acute withdrawal and persist. Some symptoms, however, including insomnia and negative affect may begin prior to the development of substance dependence [59] and continue to persist during protracted abstinence. Therefore, we prefer the term protracted abstinence symptoms [60], because it is descriptive of symptoms that are evident after the period of acute withdrawal without making any assumptions about chronology. (Nevertheless, the clinical implications of such chronological differences in symptom onset are worthy of further study.) A third class of symptoms, although not included in DSM-IV criteria for any substance withdrawal disorders, consists of craving or urges to use, which may also be a candidate for a universal symptom of protracted abstinence.

The conceptual framework of universal protracted abstinence symptoms proposes that clinical symptoms (such as sleep disturbances, negative affect, and craving) are manifestations of underlying neurobiological abnormalities, which are common to addictions across drugs of abuse.

\section{Sleep disturbance as a predictor of treatment outcome}

Several properties of sleep disturbance suggest that investigating their role in addiction may be particularly advantageous in furthering our knowledge about predicting treatment outcome. While there are numerous advantages to be considered, we focus on four that are particularly salient to the hypothesis presented.

First, as discussed above, sleep disturbances occur commonly with use and withdrawal across a number of addictive substances. This literature has recently been reviewed for dependent users of alcohol [61], cannabis [62,63], cocaine [62,64,65], nicotine [66], opioids [67], and hallucinogens such as MDMA $[62,68]$. In addition, sedative-hypnotics drugs, which are a mainstay of insomnia treatment worldwide, are associated with abuse and dependence, and ongoing sleep disturbance is common among individuals that either abuse or become dependent on sedative-hypnotics [51-54].

Second, unlike the other proposed universal protracted abstinence symptoms (craving and negative affect), sleep is the only one that can directly be studied objectively, whereas craving and negative affect cannot be studied without relying on subjective self-report of the experience. While neurophysiological correlates of self-reported craving [69-71] and negative affect [72] in addicted individuals can be studied, one really only knows that people are having these experiences if they say they are. By contrast, sleep is defined neurophysiologically as measured by polysomnography. Thus, it is known and measurable when people are asleep without them having to say so. Nevertheless, sleep can also be studied by correlating neurophysiological measures with subjective reports. When this is done, important discrepancies between self-reported and objectively measured sleep become apparent to sleep researchers and clinicians [73]. Individuals commonly underestimate or overestimate how much time they spent sleeping and awake during the night, as well as how long it took them to fall asleep. Moreover, such discrepancies have recently been reported in alcohol-dependent individuals [39,74]. By inference, therefore, correlations between neurophysiological measures and either self-reported craving or negative affect are likely subject to similar discrepancies. With sleep, however, polysomnography represents the gold standard of measurement, whereas no such gold standard exists for craving or negative affect.

Third, sleep is an unconscious activity. With the possible exception of lucid dreaming [75], what happens during sleep is not under our conscious control. Likewise, much of what happens during addiction is not under the conscious control of its sufferers. From a diagnostic perspective, loss of control or impaired control over use of a substance has long been recognized as the sine qua non of addiction. Puzzling to both addicted individuals and those who observe them, they ingest substances recurrently despite every conscious reason and desire not to. From a neurobiological perspective, such puzzling behavior has been attributed to alterations in subcortical and limbic system activity that operate outside a conscious level. Therefore, sleep offers a window into the activity of the brain in its unconscious state, which may potentially provide clues about the unconscious brain activity that underlies and drives addiction [30-33].

Finally, addiction researchers have prolific allies in the study of sleep. Sleep medicine is a recognized specialty that is informed by an extensive base of scientific evidence, much of which is published in at least 11 English-language sleep-specific journals [76]. In addition, both basic and clinical research are generating new knowledge about the neurobiology [77-79] and genetics [80] of sleep, some of which has particular relevance for the study of addictions [81,82]. Therefore, ongoing research activity regarding the effects of several different drugs of abuse on sleep is of interest to both sleep and addiction researchers [59,83-92].

\section{Implications}

\section{Research}

Despite over 30 years of evidence that addiction-related sleep disturbances are predictors of relapse, this area of research is still in its infancy. While details of a comprehensive research agenda are beyond the scope of this article, a few next steps for studying sleep as a predictor of relapse are offered. As discussed above, the current evidence for linking sleep and relapse is strongest for alcohol dependence, because it is the best studied. Additional studies on the potential relationship between sleep disturbances and 
relapse are needed for dependence on amphetamines, cannabis, cocaine, nicotine, and opioids.

Sleep measures should be considered for inclusion in all randomized clinical trials and naturalistic studies of treatment outcome. Although polysomnography is the gold standard, much information could be gained by simpler measures such as actigraphy, sleep logs, and self-report instruments. Unfortunately, these measures have not been validated specifically for sleep disturbances that occur among patients with addiction. Validating sleep measures in addicted populations can lead to consensus about which ones are most useful in clinical research. Furthermore, validation studies will decrease the number of instruments currently employed and allow for better comparability between studies.

The mechanisms for a relationship between sleep disturbance and relapse is unknown and an area for further study. One possibility is that insomnia is linked to co-occurring psychiatric disorders that worsen the course of substance dependence, particularly mood disorders, anxiety disorders, and attention deficit disorder, which all have well-described sleep disturbances. Another possibility is that insomnia is an indicator of severity of dependence, which would be expected to increase relapse rates. Third, insomnia may be linked to impulsivity [93], which in turn is linked to relapse [94]. Fourth, it is possible that chronic sleep deprivation from insomnia adversely affects cerebral executive functions such as judgment during high relapse-risk situations. Fifth, it is possible that patients relapse to substances as an attempt to self-medicate their sleep disturbance, which worsens during and persists after acute withdrawal.

Even after accounting for all of these factors, which are not mutually exclusive, we believe that addiction to substances is associated with dysfunction in regions of the brain that regulate sleep. In this regard, animal studies are particularly conducive for research on dysfunctional brain systems, which overlap in the pathogenesis of both addiction and sleep disturbance.

\section{Treatment}

The conventional wisdom among addiction treatment professionals is that both the pharmacological effects of drugs and the psychosocial stressors associated with addiction disrupt sleep. This is reasonable, except when patients are subsequently told that their natural sleep rhythms will return to normal with abstinence from substances and recovery from addiction. While this may be true for some patients, it is not true for everyone. Indeed, sleep disturbances can persist for months to years following initiation of abstinence [37], if they do not result in relapse before then. Therefore, other approaches may be indicated and have been reviewed elsewhere [35,36]. It deserves emphasis, however, that although insomnia may predict relapse, it is unproven that treatment of insomnia prevents relapse. For example, one recent randomized controlled trial of trazodone (a sedating antidepressant) vs. placebo found that alcohol-dependent participants receiving active medication had improved sleep but drank more frequently and heavily during the study [95]. Although the explanation for this finding is unclear at this time, clinicians should use medication judiciously, employ behavioral techniques whenever possible, and monitor dependent patients with sleep disturbances closely.

\section{Summary}

Measures of sleep disturbance in substance-dependent patients are common across different drugs of abuse and persist following the course of acute withdrawal into the period of protracted abstinence. Sleep disturbances are theorized to reflect neurobiological dysfunction, increase relapse risk, and be amenable to pharmaco- therapy when the mechanisms underlying addiction and sleep disturbance are better understood. Although the current evidence is strongest for alcohol addiction, we have specifically examined the hypothesis that persons who are recovering from an addiction to any psychoactive substance and have a sleep disturbance are at an increased risk of relapse compared to those without a sleep disturbance. Sleep disturbance can include both objectively measured and subjectively reported problems involved with falling asleep, staying asleep, distressing dreams, or inability to progress through normal stages of sleep. Sleep disturbance was further described as belonging to a group of universal withdrawal symptoms or universal symptoms of protracted abstinence. Negative affect and craving (or urges to use substances) are the other two members of the group. What makes these symptoms universal is their occurrence during withdrawal and prolonged abstinence from each of the most frequently used addictive substances (alcohol, amphetamines, cannabis, cocaine, nicotine, opioids, and sedative-hypnotics). What makes sleep most unique when compared to negative affect and craving is that objective measurement (via polysomnography) is possible, whereas the other two require subjective self-report to define their presence. Objective measurement will allow more direct correlations with other neurobiological mediators of addiction. Future research will determine if hallucinogens other than MDMA, inhalants, and phencyclidine/ketamine are also characterized by sleep disturbance.

\section{Conflict of interest}

None declared.

\section{Acknowledgments}

The authors acknowledge funding from NIH Grants K24 AA00304 and R03 DA027832.

The sources that provided funding had no role in the collection, analysis and interpretation of data; in the writing of the manuscript; and in the decision to suit the manuscript for publication.

\section{References}

[1] Bauer LO, Covault J, Harel O, et al. Variation in GABRA2 predicts drinking behavior in project MATCH subjects. Alcohol Clin Exp Res 2007;31:1780-7.

[2] Finckh U, Rommelspacher $\mathrm{H}$, Kuhn $\mathrm{S}$, et al. Influence of the dopamine D2 receptor (DRD2) genotype on neuroadaptive effects of alcohol and the clinical outcome of alcoholism. Pharmacogenetics 1997;7:271-81.

[3] Florez G, Saiz P, Garcia-Portilla P, et al. Association between the Stin2 VNTR polymorphism of the serotonin transporter gene and treatment outcome in alcohol-dependent patients. Alcohol Alcohol 2008;43:516-22.

[4] Pinto E, Reggers J, Gorwood P, et al. The short allele of the serotonin transporter promoter polymorphism influences relapse in alcohol dependence. Alcohol Alcohol 2008;43:398-400.

[5] Wojnar M, Brower KJ, Strobbe S, et al. Association between Val66Met brainderived neurotrophic factor (BDNF) gene polymorphism and post-treatment relapse in alcohol dependence. Alcohol Clin Exp Res 2009;33:693-702.

[6] Wrase J, Makris N, Braus DF, et al. Amygdala volume associated with alcohol abuse relapse and craving. Am J Psychiatry 2008;165:1179-84.

[7] Adinoff B, Junghanns K, Kiefer F, Krishnan-Sarin S. Suppression of the HPA axis stress-response: implications for relapse. Alcohol Clin Exp Res 2005;29:1351-5.

[8] Heinz A, Dettling M, Kuhn S, et al. Blunted growth hormone response is associated with early relapse in alcohol-dependent patients. Alcohol Clin Exp Res 1995;19:62-5.

[9] George DT, Rawlings R, Eckardt MJ, Phillips MJ, Shoaf SE, Linnoila M. Buspirone treatment of alcoholism: age of onset, and cerebrospinal fluid 5hydroxyindolacetic acid and homovanillic acid concentrations, but not medication treatment, predict return to drinking. Alcohol Clin Exp Res 1999;23:272-8.

[10] Guardia J, Catafau AM, Battle F, et al. Striatal dopaminergic $D_{2}$ receptor density measured by $\left[{ }^{123} \mathrm{I}\right]$ iodobenzamide SPECT in the prediction of treatment outcome of alcohol-dependent patients. Am J Psychiatry 2000;157:127-9.

[11] Heinz A, Lichtenberg-Kraag B, Baum SS, et al. Evidence for prolonged recovery of dopaminergic transmission after detoxification in alcoholics with poor treatment outcome. J Neural Transm Gen Sect 1995;102:149-57. 
[12] Junghanns K, Backhaus J, Tietz U, et al. Impaired serum cortisol stress response is a predictor of early relapse. Alcohol Alcohol 2003;38:189-93.

[13] Kiefer F, Jahn H, Otte C, Demiralay C, Wolf K, Wiedemann K. Increasing leptin precedes craving and relapse during pharmacological abstinence maintenance treatment of alcoholism. J Psychiatr Res 2005;39:545-51.

[14] Kiefer F, Jahn H, Otte C, Naber D, Wiedemann K. Hypothalamic-pituitaryadrenocortical axis activity: a target of pharmacological anticraving treatment? Biol Psychiatry 2006;60:74-6.

[15] Markianos M, Lykouras L, Moussas G, Hatzimanolis J. Changes in dopamine receptor responsivity during alcohol detoxification may predict relapse. Drug Alcohol Depend 2001;64:363-5.

[16] Rasmusson AM, Wu R, Paliwal P, Anderson GM, Krishnan-Sarin S. A decrease in the plasma DHEA to cortisol ratio during smoking abstinence may predict relapse: a preliminary study. Psychopharmacology (Berl) 2006;186:473-80.

[17] Schmidt LG, Dettling M, Graef KJ, et al. Reduced dopaminergic function in alcoholics is related to severe dependence. Biol Psychiatry 1996;39:193-8.

[18] Grusser SM, Wrase J, Klein S, et al. Cue-induced activation of the striatum and medial prefrontal cortex is associated with subsequent relapse in abstinent alcoholics. Psychopharmacology 2004;175:296-302.

[19] Heinz A, Wrase J, Kahnt T, et al. Brain activation elicited by affectively positive stimuli is associated with a lower risk of relapse in detoxified alcoholic subjects. Alcohol Clin Exp Res 2007;31:1138-47.

[20] Paulus MP, Tapert SF, Schuckit MA. Neural activation patterns of methamphetamine-dependent subjects during decision making predict relapse. Arch Gen Psychiatry 2005;62:761-8.

[21] Bauer LO. Electroencephalographic and autonomic predictors of relapse in alcohol-dependent patients. Alcohol Clin Exp Res 1994;18(3):755-60.

[22] Bauer LO. Frontal P300 decrements, childhood conduct disorder, family history, and the prediction of relapse among abstinent cocaine abusers. Drug Alcohol Depend 1997;44:1-10.

[23] Bauer LO. Predicting relapse to alcohol and drug abuse via quantitative electroencephalography. Neuropsychopharmacology 2001;25:332-40.

[24] Glenn SW, Sinha R, Parsons OA. Electrophysiological indices predict resumption of drinking in sober alcoholics. Alcohol 1993;10:89-95.

[25] Saletu-Zyhlarz GM, Arnold O, Anderer P, et al. Differences in brain function between relapsing and abstaining alcohol-dependent patients, evaluated by EEG mapping. Alcohol Alcohol 2004;39:233-40.

[26] Winterer G, Kloppel B, Heinz A, et al. Quantitative EEG (QEEG) predicts relapse in patients with chronic alcoholism and points to a frontally pronounced cerebral disturbance. Psychiatry Res 1998;78(1-2):101-13.

[27] Brower KJ, Aldrich MS, Hall JM. Polysomnographic and subjective sleep predictors of alcoholic relapse. Alcohol Clin Exp Res 1998;22:1864-71.

[28] Drummond SPA, Gillin JC, Smith TL, DeModena A. The sleep of abstinent pure primary alcoholic patients: natural course and relationship to relapse. Alcohol Clin Exp Res 1998;22:1796-802.

[29] Gillin JC, Smith TL, Irwin M, Butters N, Demodena A, Schuckit M. Increased pressure for rapid eye movement sleep at time of hospital admission predicts relapse in nondepressed patients with primary alcoholism at 3-month followup. Arch Gen Psychiatry 1994;51:189-97.

[30] Kalivas PW, O'Brien C. Drug addiction as a pathology of staged neuroplasticity. Neuropsychopharmacology 2008;33:166-80.

[31] Heinz A, Beck A, Grusser SM, Grace AA, Wrase J. Identifying the neural circuitry of alcohol craving and relapse vulnerability. Addict Biol 2009;14:108-18.

[32] Koob GF. Neurobiological substrates for the dark side of compulsivity in addiction. Neuropharmacology 2009;56(Suppl. 1):18-31.

[33] Goldstein RZ, Craig AD, Bechara A, et al. The neurocircuitry of impaired insight in drug addiction. Trends Cogn Sci 2009;13:372-80.

[34] American Psychiatric Association. DSM-IV-TR: diagnostic and statistical manual of mental disorders. 4th ed. Text revision. Washington, DC: American Psychiatric Association; 2000.

[35] Arnedt JT, Conroy DA, Brower KJ. Treatment options for sleep disturbances during alcohol recovery. J Addict Dis 2007;26:41-54.

[36] Conroy DA, Todd Arnedt J, Brower KJ. Insomnia in patients with addictions: a safer way to break the cycle. Curr Psychiatry 2007;7(5):97-110.

[37] Brower KJ. Alcohol's effects on sleep in alcoholics. Alcohol Res Health $2001 ; 25: 110-25$

[38] Brower KJ. Insomnia, alcoholism and relapse. Sleep Med Rev 2003;7:523-39.

[39] Conroy DA, Todd Arnedt J, Brower KJ, et al. Perception of sleep in recovering alcohol-dependent patients with insomnia: relationship with future drinking. Alcohol Clin Exp Res 2006;30:1992-9.

[40] Feige B, Scaal S, Hornyak M, Gann H, Riemann D. Sleep electroencephalographic spectral power after withdrawal from alcohol in alcohol-dependent patients. Alcohol Clin Exp Res 2007;31:19-27.

[41] Malcolm R, Myrick LH, Veatch LM, Boyle E, Randall PK. Self-reported sleep, sleepiness, and repeated alcohol withdrawals: a randomized, double blind, controlled comparison of lorazepam vs. gabapentin. J Clin Sleep Med 2007;3:24-32.

[42] Choi SY. Dreams as a prognostic factor in alcoholism. Am J Psychiatry 1973;130:699-702.

[43] Christo G, Franey C. Addicts' drug-related dreams: their frequency and relationship to six-month outcomes. Subst Use Misuse 1996;31:1-15.

[44] Flowers LK, Zweben JE. The changing role of "using" dreams in addiction recovery. J Subst Abuse Treat 1998;15:193-200.

[45] Sofuoglu M, Dudish-Poulsen S, Poling J, Mooney M, Hatsukami DK. The effect of individual cocaine withdrawal symptoms on outcomes in cocaine users. Addict Behav 2005;30:1125-34.
[46] Gann H, Feige B, Hohagen F, van Calker D, Geiss D, Dieter R. Sleep and the cholinergic rapid eye movement sleep induction test in patients with primary alcohol dependence. Biol Psychiatry 2001;50:383-90.

[47] Boutou AK, Tsiata EA, Pataka A, Kontou PK, Pitsiou GG, Argyropoulou P. Smoking cessation in clinical practice: predictors of six-month continuous abstinence in a sample of Greek smokers. Primary Care Respir J 2008;17: 32-8.

[48] Foulds J, Gandhi KK, Steinberg MB, et al. Factors associated with quitting smoking at a tobacco dependence treatment clinic. Am J Health Behav 2006;30:400-12.

[49] Scharf DM, Dunbar MS, Shiffman S. Smoking during the night: prevalence and smoker characteristics. Nicotine Tob Res 2008;10:167-78.

[50] Dijkstra BA, De Jong CA, Krabbe PF, van der Staak CP. Prediction of abstinence in opioid-dependent patients. J Addict Med 2008;2:194-201.

[51] Becker WC, Fiellin DA, Desai RA. Non-medical use, abuse and dependence on sedatives and tranquilizers among U.S. adults: psychiatric and sociodemographic correlates. Drug Alcohol Depend 2007;90:280-7.

[52] Carter LP, Griffiths RR, Suess PE, Casada JH, Wallace CL, Roache JD. Relative abuse liability of indiplon and triazolam in humans: a comparison of psychomotor, subjective, and cognitive effects. J Pharmacol Exp Ther 2007;322:749-59.

[53] Victorri-Vigneau C, Dailly E, Veyrac G, Jolliet P. Evidence of zolpidem abuse and dependence: results of the French Centre for Evaluation and Information on Pharmacodependence (CEIP) network survey. $\mathrm{Br} \mathrm{J}$ Clin Pharmacol 2007;64:198-209.

[54] Griffiths RR, Johnson MW. Relative abuse liability of hypnotic drugs: conceptual framework and algorithm for differentiating among compounds. J Clin Psychiatry 2005;66(Suppl. 9):31-41.

[55] West R, Gossop M. Overview: a comparison of withdrawal symptoms from different drug classes. Addiction 1994;89:1483-9.

[56] Aston-Jones G, Harris GC. Brain substrates for increased drug seeking during protracted withdrawal. Neuropharmacology 2004;47(Suppl. 1):167-79.

[57] Martinotti G, Nicola MD, Reina D, et al. Alcohol protracted withdrawal syndrome: the role of anhedonia. Subst Use Misuse 2008;43:271-84.

[58] Hornyak M, Haas P, Veit J, Gann H, Riemann D. Magnesium treatment of primary alcohol-dependent patients during subacute withdrawal: an open pilot study with polysomnography. Alcohol Clin Exp Res 2004;28:1702-9.

[59] Wong MM, Brower KJ, Zucker RA. Childhood sleep problems, early onset of substance use and behavioral problems in adolescence. Sleep Med 2009;10:787-96.

[60] Coffey SF, Dansky BS, Carrigan MH, Brady KT. Acute and protracted cocaine abstinence in an outpatient population: a prospective study of mood, sleep and withdrawal symptoms. Drug Alcohol Depend 2000;59:277-86.

[61] Krystal AD, Thakur M, Roth T. Sleep disturbance in psychiatric disorders: effects on function and quality of life in mood disorders, alcoholism, and schizophrenia. Ann Clin Psychiatry 2008;20:39-46.

[62] Schierenbeck T, Riemann D, Berger M, Hornyak M. Effect of illicit recreational drugs upon sleep: cocaine, ecstasy and marijuana. Sleep Med Rev 2008;12:381-9.

[63] Jacobus J, Bava S, Cohen-Zion M, Mahmood O, Tapert SF. Functional consequences of marijuana use in adolescents. Pharmacol Biochem Behav 2009;92:559-65.

[64] Valladares EM, Irwin MR. Polysomnographic sleep dysregulation in cocaine dependence. ScientificWorldJournal 2007;7:213-6.

[65] Morgan PT, Malison RT. Cocaine and sleep: early abstinence. ScientificWorldJournal 2007;7:223-30.

[66] Colrain IM, Trinder J, Swan GE. The impact of smoking cessation on objective and subjective markers of sleep: review, synthesis, and recommendations. Nicotine Tob Res 2004;6:913-25.

[67] Wang D, Teichtahl H. Opioids, sleep architecture and sleep-disordered breathing. Sleep Med Rev 2007;11:35-46.

[68] McCann UD, Ricaurte GA. Effects of ( \pm ) 3,4-methylenedioxymethamphetamine (MDMA) on sleep and circadian rhythms. ScientificWorldJournal 2007;7:231-8

[69] Leggio L, Ferrulli A, Malandrino N, et al. Insulin but not insulin growth factor-1 correlates with craving in currently drinking alcohol-dependent patients. Alcohol Clin Exp Res 2008;32:450-8.

[70] Leggio L, Ferrulli A, Cardone S, et al. Relationship between the hypothalamicpituitary-thyroid axis and alcohol craving in alcohol-dependent patients: a longitudinal study. Alcohol Clin Exp Res 2008;32:2047-53.

[71] Leggio L, Ferrulli A, Cardone S, et al. Renin and aldosterone but not the natriuretic peptide correlate with obsessive craving in medium-term abstinent alcohol-dependent patients: a longitudinal study. Alcohol 2008;42:375-81.

[72] Sinha R, Fox HC, Hong KA, Bergquist K, Bhagwagar Z, Siedlarz KM. Enhanced negative emotion and alcohol craving, and altered physiological responses following stress and cue exposure in alcohol dependent individuals. Neuropsychopharmacology 2009;34:1198-208.

[73] Means MK, Edinger JD, Glenn DM, Fins AI. Accuracy of sleep perceptions among insomnia sufferers and normal sleepers. Sleep Med 2003;4:285-96.

[74] Currie SR, Malhotra S, Clark S. Agreement among subjective, objective, and collateral measures of insomnia in postwithdrawal recovering alcoholics. Behav Sleep Med 2004;2:148-61.

[75] Voss U, Holzmann R, Tuin I, Hobson JA. Lucid dreaming: a state of consciousness with features of both waking and non-lucid dreaming. Sleep 2009;32:1191-200. 
[76] U.S. National Library of Medicine, and National Institutes of Health. PubMed Home Page. Search of Journals Database containing the word "Sleep". Available at: http://www.ncbi.nlm.nih.gov/pubmed/ [accessed 09/23/2009].

[77] Desseilles M, Dang-Vu T, Schabus M, Sterpenich V, Maquet P, Schwartz S Neuroimaging insights into the pathophysiology of sleep disorders. Sleep 2008;31:777-94.

[78] Steiger A. Neurochemical regulation of sleep. J Psychiatr Res 2007;41(7): 537-52.

[79] Altena E, Van Der Werf YD, Sanz-Arigita EJ, et al. Prefrontal hypoactivation and recovery in insomnia. Sleep 2008;31:1271-6.

[80] Dauvilliers Y, Tafti M. The genetic basis of sleep disorders. Curr Pharm Des 2008;14:3386-95.

[81] Volkow ND, Wang GJ, Telang F, et al. Sleep deprivation decreases binding of [11C]raclopride to dopamine D2/D3 receptors in the human brain. J Neurosci 2008;28:8454-61.

[82] Perreau-Lenz S, Zghoul T, Spanagel R. Clock genes running amok. Clock genes and their role in drug addiction and depression. EMBO Rep 2007;8:S20-3 [Spec No].

[83] Bolla KI, Lesage SR, Gamaldo CE, et al. Sleep disturbance in heavy marijuana users. Sleep 2008;31:901-8.

[84] Killgore WD, Kahn-Greene ET, Grugle NL, Killgore DB, Balkin TJ. Sustaining executive functions during sleep deprivation: a comparison of caffeine dextroamphetamine, and modafinil. Sleep 2009;32:205-16.

[85] Perez AY, Kirkpatrick MG, Gunderson EW, et al. Residual effects of intranasa methamphetamine on sleep, mood, and performance. Drug Alcohol Depend 2008;94:258-62.

[86] Kirilly E, Molnar E, Balogh B, et al. Decrease in REM latency and changes in sleep quality parallel serotonergic damage and recovery after MDMA: a longitudinal study over 180 days. Int J Neuropsychopharmacol 2008;11:795-809.

[87] Zhang L, Samet J, Caffo B, Bankman I, Punjabi NM. Power spectral analysis of EEG activity during sleep in cigarette smokers. Chest 2008;133:427-32.

[88] Peles E, Schreiber S, Adelson M. Documented poor sleep among methadonemaintained patients is associated with chronic pain and benzodiazepine abuse but not with methadone dose. Eur Neuropsychopharmacol 2009;19:581-8.

[89] Sharkey KM, Kurth ME, Corso RP, Brower KJ, Millman RP, Stein MD. Home polysomnography in methadone maintenance patients with subjective sleep complaints. Am J Drug Alcohol Abuse 2009;35:178-82.

[90] Irwin MR, Olmstead R, Valladares EM, Breen EC, Ehlers CL. Tumor necrosis factor antagonism normalizes rapid eye movement sleep in alcohol dependence. Biol Psychiatry 2009;66:191-5.

[91] Colrain IM, Crowley KE, Nicholas CL, Padilla M, Baker FC. The impact of alcoholism on sleep evoked delta frequency responses. Biol Psychiatry 2009;66:177-84.

[92] Chueh KH, Yang MS, Chen CS, Chiou SM. Poor sleep quality and alcohol use problems among elderly Taiwanese aboriginal women. Int Psychogeriatr 2009;21:593-9.

[93] Schmidt RE, Gay P, Van der Linden M. Facets of impulsivity are differentially linked to insomnia: evidence from an exploratory study. Behav Sleep Med 2008;6:178-92.

[94] Muller SE, Weijers HG, Boning J, Wiesbeck GA. Personality traits predict treatment outcome in alcohol-dependent patients. Neuropsychobiology 2008;57:159-64.

[95] Friedmann PD, Rose JS, Swift R, Stout RL, Millman RP, Stein MD. Trazodone for sleep disturbance after alcohol detoxification: a double-blind, placebocontrolled trial. Alcohol Clin Exp Res 2008;32:1652-60. 